Open Access

\title{
Age-related increases in amyloid beta and membrane attack complex: evidence of inflammasome activation in the rodent eye

Tom Zhao ${ }^{1 \dagger}$, Jiangyuan Gao ${ }^{1 \dagger}$, Jenifer Van ${ }^{1}$, Eleanor To ${ }^{1}$, Aikun Wang ${ }^{1}$, Sijia Cao ${ }^{1}$, Jing Z. Cui ${ }^{1}$, Jian-Ping Guo ${ }^{2}$, Moonhee Lee ${ }^{2}$, Patrick L. McGeer ${ }^{2}$ and Joanne A. Matsubara ${ }^{{ }^{*}}$

\begin{abstract}
Background: The membrane attack complex (MAC) is a key player in the pathogenesis of age-related macular degeneration (AMD) and is a putative activator of the NLRP3 inflammasome. Amyloid beta (Aß), a component of drusen deposits, has also been implicated in inflammasome activation by our work and those of others. However, the interactions of MAC and $A \beta$ are still poorly understood, especially their roles in aging and retinal degenerative pathologies. Since inflammasome activation may represent a key cellular pathway underlying age-related chronic inflammation in the eye, the purpose of this study is to identify the effects associated with MAC and inflammasome activation in the retinal pigment epithelium (RPE)/choroid and to evaluate the therapeutic merits of MAC suppression.

Methods: Adult Long-Evans rats were divided into treatment and control groups. Treatment groups received oral aurin tricarboxylic acid complex (ATAC), a MAC inhibitor, in drinking-water, and control groups received drinking-water alone (No ATAC). Groups were sacrificed at 7.5 or 11.5 months, after approximately 40 days of ATAC treatment. To study age-related changes of $A \beta$ and MAC in RPE/choroid, naive animals were sacrificed at 2.5, 7.5, and 11.5 months. Eye tissues underwent immunohistochemistry and western blot analysis for MAC, A $\beta$, NF-KB activation, as well as cleaved caspase-1 and IL-18. Vitreal samples were collected and assessed by multiplex assays for secreted levels of IL-18 and IL-1 $\beta$. Statistical analyses were performed, and significance level was set at $p \leq 0.05$.
\end{abstract}

Results: In vivo studies demonstrated an age-dependent increase in MAC, AB, and NF-KB activation in the RPE/choroid. Systemic ATAC resulted in a prominent reduction in MAC formation and a concomitant reduction in inflammasome activation measured by cleaved caspase-1 and secreted levels of IL-18 and IL-1 $\beta$, but not in NF-KB activation. In vitro studies demonstrated Aß-induced MAC formation on RPE cells.

Conclusions: Age-dependent increases in $A \beta$ and MAC are present in the rodent outer retina. Our results suggest that suppressing MAC formation and subsequent inflammasome activation in the RPE/choroid may reduce chronic low-grade inflammation associated with IL-18 and IL-1 $\beta$ in the outer retina.

Keywords: Age-related macular degeneration, Membrane attack complex, Amyloid beta, NLRP3 inflammasome, NF-KB, RPE/choroid

\footnotetext{
*Correspondence: jms@mail.ubc.ca

${ }^{\dagger}$ Equal contributors

'Department of Ophthalmology and Visual Sciences, Faculty of Medicine, University of British Columbia, 2550 Willow Street, Vancouver V5Z 3N9BC, Canada

Full list of author information is available at the end of the article
} 


\section{Introduction}

Age-related macular degeneration (AMD), the leading cause of irreversible blindness in the elderly in developed countries, is a condition of the central retina, characterized by retinal pigment epithelium (RPE) atrophy and photoreceptor loss. Advanced chronological age is an important risk factor for AMD. In North America, the prevalence of AMD increases dramatically with age from $10 \%$ in individuals at 55 to 65 years of age, to $30 \%$ at 75 to 85 years of age [1]. Key to understanding the effects of aging on the pathogenesis of retinal degenerative diseases are the cellular pathways that become dysregulated with age [2-4].

For example, aging is associated with the dysregulation in the complement cascade, part of the innate immune response. The complement cascade causes opsonization and agglutination, as well as cell lysis by the formation of the membrane attack complex (MAC) [5]. Genetic studies showed that certain variants of the complement factor $\mathrm{H}(\mathrm{CFH})$ gene, an inhibitor of the alternative pathway, can increase the risk of AMD by up to sixfold in patients with the at-risk variant [6]. Postmortem eyes genotyped for $\mathrm{CFH}$ at-risk variants have increased $\mathrm{MAC}$ levels in the RPE/choroid [7, 8]. Moreover, in dry AMD patients, those with a CFH $\mathrm{Y} 402 \mathrm{H}$ variant have elevated systemic levels of interleukin-6 (IL-6), tumor necrosis factor (TNF- $\alpha$ ), and IL-18 [9]. In addition to genetic influences, aging also contributes to the dysregulation of the complement system, as evidenced by the association of activated complement products and increased MAC deposition in the RPE/choroid with advanced age [10-13].

While MAC deposition may cause cell lysis, it may also occur at sublytic levels that promote chronic, low-grade pro-inflammation. This type of chronic, local inflammation in the outer retina has been hypothesized to lead to degenerative changes in RPE function [14]. Recent studies have suggested that MAC may mediate activation of the NLRP3 inflammasome [15, 16]. The inflammasome is a multi-protein complex that activates caspase- 1 and produces the pro-inflammatory cytokines IL- $1 \beta$ and IL-18, which in turn have been linked to RPE atrophy $[17,18]$. Whether MAC promotes inflammasome activation in the $\mathrm{RPE} /$ choroid is not known and is the premise of this study. We postulate that sublytic MAC increases with age, promotes activation of the inflammasome, and thereby, dysregulates RPE function. To ameliorate MAC-induced inflammasome activation on RPE, we also explore the effects of an agent, aurin tricarboxylic acid complex (ATAC), which has been shown to inhibit MAC formation in mice and humans. Specifically, ATAC acts both to inhibit the formation of the $\mathrm{C} 3$ convertase and to block the addition of $\mathrm{C} 9$ to the $\mathrm{C} 5 \mathrm{~b}-8$ complex and thereby inhibits MAC $[19,20]$. Here, we examine the age-related increase in MAC, the efficacy of ATAC in lowering levels of sublytic MAC, and a subsequent, corresponding reduction in inflammasome activation in the rat RPE/choroid.

\section{Methods}

\section{In vivo studies}

The animal procedures were approved by the Animal Care Committee of the University of British Columbia, conformed to the guidelines of the Canadian Council on Animal Care and were in accordance with the Resolution on the Use of Animals in Research of the Association of Research in Vision and Ophthalmology. Adult Long-Evans rats (Charles River, Wilmington MA) were divided into four groups. Group $1(N=6)$ comprised 6month-old rats treated with oral administration of ATAC for 40 days and sacrificed at the age of 7.5 months. A dosage of $60 \mathrm{mg} / 100 \mathrm{~mL}$ (in drinking-water) was chosen based on efficacy observed in an earlier study [19]. Group $2(N=6)$ comprised untreated 6-month-old rats (controls) sacrificed at the age of 7.5 months. Group $3(N=6)$ comprised 10-month-old rats treated with ATAC in drinking-water $(60 \mathrm{mg} / 100 \mathrm{~mL})$ for 40 days and sacrificed at the age of 11.5 months. Group $4(N=6)$ comprised untreated 10-month-old rats (controls) sacrificed at 11.5 months. Additional untreated naive animals were sacrificed at 2.5, 6, 7.5, or 11.5 months, and retinal tissues were used to demonstrate age-related changes in MAC, $A \beta$, and NF-kB activation. At the study endpoints, animals were anesthetized, whole blood drawn for serum analysis, and then euthanized. Eyes were immediately enucleated and frozen (western blot and ELISA) or fixed in $4 \%$ paraformaldehyde in Dulbecco's phosphate-buffered saline (Invitrogen, Carlsbad CA) for 48-72 h prior to embedding in paraffin.

\section{Fibrillar $A \beta_{1-40}$ preparation}

The lyophilized, synthetic $A \beta_{1-40}$ peptide in its $\mathrm{HCl}$ salt form was purchased from American Peptide (Sunnyvale, CA). We chose $A \beta_{1-40}$ peptide over its structurally similar but more toxic, Alzheimer's disease-specific, form of $A \beta_{1-42}$ peptide based on earlier studies that demonstrated the presence of $A \beta_{1-40}$ in drusen deposits in postmortem human eyes and its effects on upregulation of complement genes in RPE cells in vitro [21, 22]. Fibrillar $A \beta_{1-40}$ was prepared according to published protocols $[23,24]$. Briefly, the synthetic $A \beta_{1-40}$ peptide was reconstituted in sterile distilled $\mathrm{H}_{2} \mathrm{O}$ and incubated at room temperature for $30 \mathrm{~min}$, then evaporated by speed vacuum for $1.5 \mathrm{~h}$ resulting in thin transparent $A \beta_{1-40}$ peptide film. $A \beta_{1-40}$ peptide film was reconstituted in $100 \%$ dimethyl sulfoxide to a concentration of $1 \mathrm{mM}$, and further diluted in Tris-buffered saline (TBS; $20 \mathrm{mM}$ Tris- $\mathrm{HCl}, 100 \mathrm{mM} \mathrm{NaCl}, \mathrm{pH} 7.4,37^{\circ} \mathrm{C}$ ) to produce the $\mathrm{A} \beta_{1-40}$ stock solution of $100 \mu \mathrm{M}$. A longitudinal incubation assay consisting of six sampling time points at 
$37{ }^{\circ} \mathrm{C}$ ( 24 h to 2 weeks) was set up to optimize the conditions for fibrillar $A \beta_{1-40}$. Based on the protein separation, the sample at 1-week incubation time was selected, due to its higher fibrillar and lower oligomeric contents, which was then further diluted to $0.3 \mu \mathrm{M}$ (final concentration) for the in vitro stimulation studies (Fig. 2) [22, 25-27].

\section{In vitro complement activation assay on ARPE-19 cells}

An in vitro assay was used to assess whether the fibrillar $\mathrm{A} \beta_{1-40}$ induces MAC formation and deposition on ARPE19 cells. Briefly, cells were seeded and cultured in 8chambered glass slides. Normal human serum (NHS) (25\%) (CompTech, Tyler, TX) was added to the cell cultures with $0.3 \mu \mathrm{M}$ fibrillar $\mathrm{A} \beta_{1-40}$ for $24 \mathrm{~h}$. Positive controls included zymosan stimulation $(10 \mu \mathrm{g} / \mathrm{ml}$, Sigma Aldrich, St. Louis MO) with 25 \% NHS. Negative controls included $25 \%$ heat-inactivated NHS (HI-NHS) with fibrillar A $\beta_{1-40}$ or zymosan, and serum-free medium with $25 \%$ NHS or HI-NHS. MAC formation was detected by immunocytochemistry (Table 1) and quantified as the percentage of RPE cells positive for MAC compared to the total number of cells per $\times 40$ field. The experiments were done in hexaplicates for each stimulation condition $(N=6)$.

\section{Quantification of ATAC and CH50 assay}

ATAC synthesis and its serum concentration analysis followed published methods [19, 20]. The final ATAC concentration was expressed in $\mu \mathrm{g}$ per $500 \mu \mathrm{L}$ of blood $(N=6)$. A CH50 hemolysis assay was used to assess complement activation in rat serum before and after ATAC administration, following published procedures [19].
Immunohistochemistry (MAC, IL-18, A $\beta$, and NF-KB)

Paraffin-embedded eye tissues were prepared and sectioned following established protocols [28]. Sections from the paired groups (7.5 $\mathrm{m}$ ATAC and No ATAC; $11.5 \mathrm{~m}$ ATAC and No ATAC) and the three age groups $(2.5,7.5$, and $11.5 \mathrm{~m})$ were processed simultaneously in order to make intensity comparisons. Primary antibodies targeting MAC, IL-18, and A $\beta$ are described in Table 1. For the negative control sections, the primary antibody was replaced with a matched non-specific isotype IgG (Sigma Aldrich). For visualization, the slides were developed using either the Vector ${ }^{\bullet}$ VIP substrate kit or Vector ${ }^{\oplus}$ AEC substrate kit.

MAC, A $\beta$, and IL-18 immunoreactivity was scored in a masked fashion and semi-quantitatively based on a $0-3$ point scale (see Fig. 1 legend). Analysis and micrographs were taken using a $\times 60$ objective lens and $\times 10$ eyepieces $(N=3)$. The immunoreactivity scores of MAC, A $\beta$, and IL-18 were averaged and normalized to the 7.5-month-old group or the untreated control group (No ATAC).

To detect the active NF- $\mathrm{kB}$, an antibody against the NF- $\mathrm{kB}$ p65 subunit was used (Table 1). Immunoreactivity was scored quantitatively, in a masked fashion, using $\mathrm{a} \times 60$ objective lens and $\times 10$ eyepieces $(N=3)$. Positive RPE nuclei were identified as containing both the red (AEC) chromogen and blue hematoxylin counterstain, thus resulting in a purple appearance distinct from the unlabeled RPE nuclei that were blue in color from only the hematoxylin counterstain. The number of NF- $\mathrm{KB}$ positive nuclei was converted to percentage of all RPE nuclei in the sample area, and normalized to the untreated control group (No ATAC) or the 7.5month-old group.

Table 1 List of primary antibodies

\begin{tabular}{|c|c|c|c|c|}
\hline Antigen & Antibody & Dilution & Source & Applications \\
\hline $\begin{array}{l}\text { Membrane attack complex } \\
\text { (MAC) }\end{array}$ & $\begin{array}{l}\text { Mouse monoclonal } \\
\text { (clone aE11) }\end{array}$ & $\begin{array}{l}1: 50(\mathrm{IHC}) \\
1: 1000(\mathrm{WB})\end{array}$ & $\begin{array}{l}\text { Dako, Burlington, } \\
\text { ON, Canada }\end{array}$ & $\begin{array}{l}\text { Immunocytochemistry } \\
\text { Western blot }\end{array}$ \\
\hline $\begin{array}{l}\text { Membrane attack complex } \\
\text { (MAC) }\end{array}$ & Rabbit polyclonal & $1: 500$ & Bloss, Woburn, MA & Immunohistochemistry \\
\hline Interleukin-18 (IL-18) & Rabbit polyclonal & $1: 100$ & $\begin{array}{l}\text { Santa Cruz Biotechnology, } \\
\text { Dallas, TX }\end{array}$ & Immunohistochemistry \\
\hline $\begin{array}{l}\text { Amyloid-beta amino acid } \\
\text { 17-24 }\left(A \beta_{17-24}\right)\end{array}$ & $\begin{array}{l}\text { Mouse monoclonal } \\
\text { anti-A } \beta_{17-24}(\text { clone } 4 G 8)\end{array}$ & $\begin{array}{l}1: 400(\mathrm{IHC}) \\
1: 1000(\mathrm{WB})\end{array}$ & BioLegend, Dedham, MA & $\begin{array}{l}\text { Immunohistochemistry } \\
\text { Western blot }\end{array}$ \\
\hline $\begin{array}{l}\text { Phosphorylated NF-kB p65 } \\
\text { (Ser 276) }\end{array}$ & Rabbit polyclonal & $\begin{array}{l}1: 75(\mathrm{IHC}) \\
1: 500(\mathrm{WB})\end{array}$ & $\begin{array}{l}\text { Santa Cruz Biotechnology, } \\
\text { Dallas, TX }\end{array}$ & $\begin{array}{l}\text { Immunohistochemistry } \\
\text { Western blot }\end{array}$ \\
\hline $\begin{array}{l}\text { Phosphorylated NF-kB p50 } \\
\text { (Ser 337) }\end{array}$ & Rabbit polyclonal & $1: 500(\mathrm{WB})$ & $\begin{array}{l}\text { Santa Cruz Biotechnology, } \\
\text { Dallas, TX }\end{array}$ & Western blot \\
\hline Caspase-1 & Mouse monoclonal & $1: 1000$ & $\begin{array}{l}\text { R\&D Systems, Minneapolis, } \\
\text { MN }\end{array}$ & Western blot \\
\hline $\begin{array}{l}\text { Amyloid-beta amino acid } \\
1-16\left(A \beta_{1-16}\right)\end{array}$ & $\begin{array}{l}\text { Mouse monoclonal } \\
\text { anti-A } \beta_{1-16}(\text { clone } 6 \mathrm{E} 10)\end{array}$ & $1: 2000$ & BioLegend, Dedham, MA & Western blot \\
\hline GAPDH & Mouse monoclonal & $1: 10,000$ & EMD Millipore, Billerica, MA & Western blot \\
\hline
\end{tabular}


A

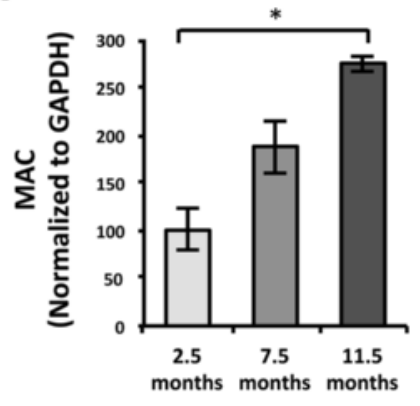

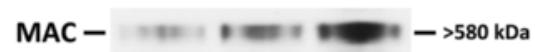

GAPDH $-\longrightarrow 36 \mathrm{kDa}$

D

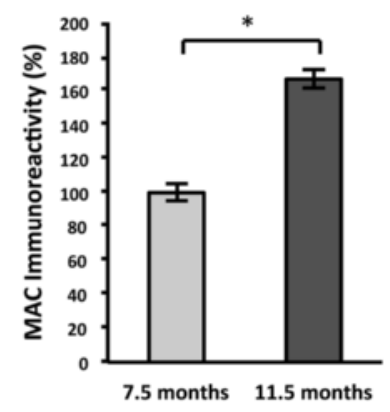

G

MAC

RPE 7.5 manths,

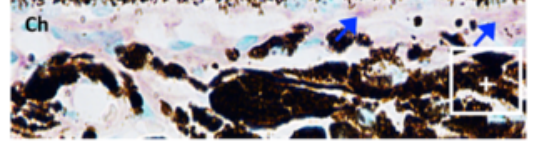

RPE

Ch

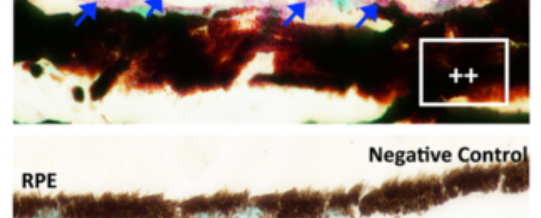

ch

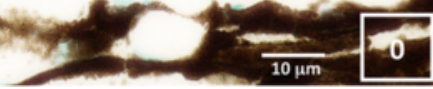

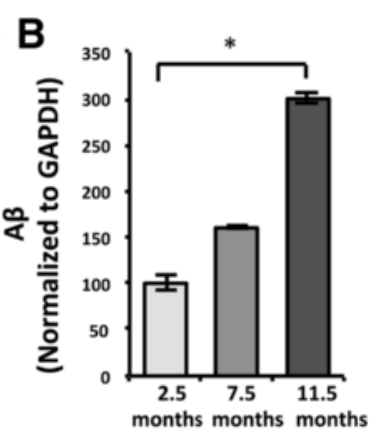

C

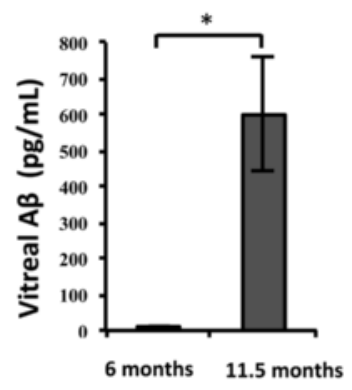

$$
\mathrm{A} \beta-\rightleftharpoons \mathrm{W}=\begin{array}{r}
170 \mathrm{kDa} \\
130 \mathrm{kDa} \\
95 \mathrm{kDa}
\end{array}
$$

GAPDH - - $-36 \mathrm{kDa}$

E

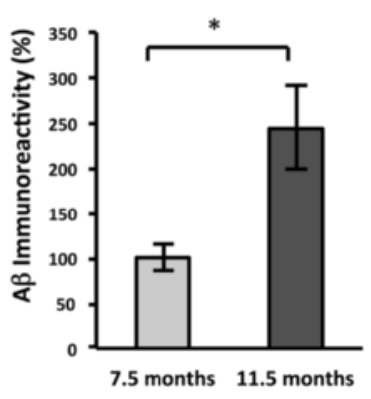

H
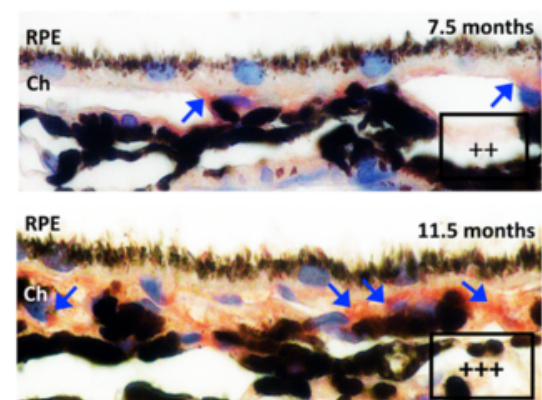

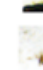

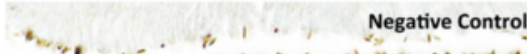
RPE '

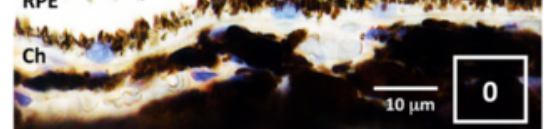

$\mathbf{F}$

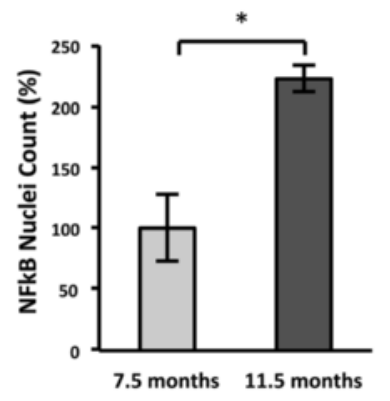

I

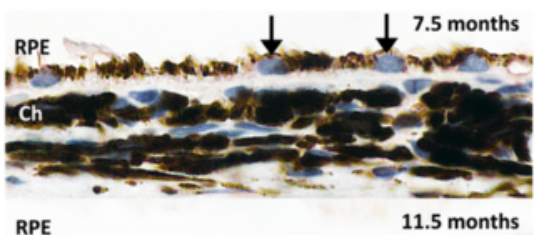

RPE 11.5 months

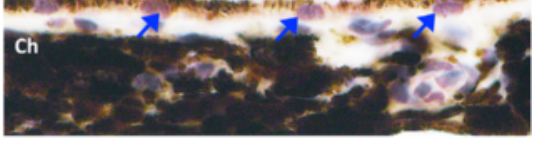

RPE Negative Control RPE Ch

Fig. 1 (See legend on next page.) 
(See figure on previous page.)

Fig. 1 Age-dependent increases of ocular MAC, A 3 and NF-KB. a Western blot analysis revealed increasing MAC levels in the rat RPE/choroid with age from 2.5 to 11.5 months old (Kruskal-Wallis, $p \leq 0.05$ ). b Western blot analysis showed enhanced accumulation of high-molecular weight $A \beta$ $(\mathrm{MW}>95 \mathrm{kDa})$ in the rat RPE/choroid with age from 2.5 to 11.5 months old (Kruskal-Wallis, $p \leq 0.05)$. c ELISA measurements showed a dramatic increase in the soluble $A \beta$ levels in the vitreous fluids of the 11.5 months old $(599.1 \mathrm{pg} / \mathrm{mL}$ ) compared to the $6 \mathrm{months}$ old group (7.5 pg/mL) (Mann-Whitney, $p \leq 0.05$ ). d e Analysis of MAC deposition (d) or A $\beta$ (e) in rat RPE/choroid demonstrated a significant increase in immunoreactivity with increasing age, with data normalized to the younger age group of 7.5 months (Mann-Whitney, $p \leq 0.05$ ). $\mathbf{f}$ NF-KB activation in RPE increased with age. The percentage of RPE cells with nuclear labeling of translocated NF-kB p65 subunit was higher in the retina of the 11.5 months old group compared to the 7.5 months old group (Mann-Whitney, $p \leq 0.05$ ). $\mathbf{g}$ Representative micrographs of MAC immunoreactivity at both ages (7.5 and 11.5 months) showed MAC deposition on the basal side of RPE and in choroid. Immunoreactivity was processed with VIP, resulting in a purple color (blue arrows) and nuclei counterstained with Methyl Green. Background immunoreactivity (0) and semi-quantitative scoring of + and ++ are given for the following examples: 7.5 months old (+), 11.5 months old (++), and negative control (0). Note the dark brown choroidal melanocytes in the 11.5 months picture appeared surrounded by red haze due to bright field illumination. $\mathbf{h}$ Representative micrographs of $A \beta$ immunoreactivity at both ages (7.5 and 11.5 months) showed positive immunolabeling on the basal side of RPE and in choroid. Immunoreactivity was processed with AEC, resulting in a red color (blue arrows) and nuclei counterstained as blue. Examples of semi-quantitative scores are given as follows: 7.5 months old $(++), 11.5$ months old $(+++)$, and negative control $(0)$. i Representative micrographs of the RPE nuclei from the

11.5 months old group showed more robust NF-KB p65 immunoreactivity than the 7.5 months old group. Positive NF-kB p65 immunolabeling is purple in RPE nuclei and indicated by blue arrows. RPE nuclei devoid of NF-KB p65 are blue and indicated by black arrows. Scale bars; 10 um. RPE retinal pigment epithelium, Ch choroid

\section{Western blot}

RPE/Bruch's membrane (BM)/choroid tissues were isolated and pooled for animals in each of the four treatment groups (groups $1-4, N=6$ ) and in each age group of the naive animals (2.5, 7.5, and 11.5 months; $N \geq 3$ ). To detect the MAC deposits, the tissue samples were homogenized in $200 \mu \mathrm{L}$ of ice-cold MAC extraction buffer (50 mM Tris- $\mathrm{HCl}$ (pH 6.8), $150 \mathrm{mM} \mathrm{NaCl}, 0.1 \%$ SDS) containing protease inhibitor cocktail (Roche Diagnostics, Indianapolis IN) [20]. To preserve the MAC protein complex, $40 \mu \mathrm{g}$ of total protein was mixed with equal volume of $2 \times$ non-reducing loading buffer, devoid of boiling, and directly subjected to 5-10 \% SDS-PAGE. Proteins were transferred to a PVDF membrane and incubated with a series of blocking buffers, primary antibody against MAC (Table 1), and HRP conjugated secondary antibody ( $\&$ D Systems, Minneapolis, MN). The enhanced chemiluminescence (ECL) method was used to detect the MAC protein bands from animal groups 1-4 and the naive animals at three different ages. The glyceraldehyde 3-phosphate dehydrogenase (GAPDH)-loading control blot was done similarly using a mouse GAPDH antibody (Table 1). All protein bands were subsequently quantified using Image $\mathrm{J}$ (NIH, Bethesda MD), and the ratio of MAC-to-GAPDH was calculated. The final relative intensity of MAC was normalized either to the youngest age group of 2.5 months or to the No ATAC control group.

To detect caspase- 1 cleavage and NF- $\mathrm{KB}$ activation, the $\mathrm{RPE} / \mathrm{BM} /$ choroid tissues were homogenized in $200 \mu \mathrm{L}$ of ice-cold RIPA buffer (Thermo Scientific, Waltham, MA) containing protease inhibitor cocktail (Roche Diagnostics). Blotting procedures followed our established protocol [28]. For GAPDH, the same membrane was incubated in stripping buffer and then re-probed with the GAPDH antibody (Table 1). The protein band intensity of cleaved caspase-1 (20kD), phosphorylated NF-кB p65 subunit (65 $\mathrm{KDa}$ ), phosphorylated NF-kB p50 subunit (50 KDa), and GAPDH $(36 \mathrm{kD})$ was individually measured using Image J and converted into ratios relative to GAPDH. The final relative intensity of cleaved caspase-1 p20 and phosphorylated NF-kB p65 was normalized to the No ATAC control group.

For western blot detection of $A \beta$, both fibrillar $A \beta_{1-40}$ preparation and the RIPA buffer-extracted RPE/BM/ choroid tissue lysates were mixed with $2 \times$ non-reducing loading buffer, devoid of boiling, and directly subjected to 5-12\% SDS-free PAGE separation. Electrophoresis was run using MES buffer (Invitrogen, pH $7.3 \sim 7.7$ ), and proteins were transferred onto a $0.2-\mu \mathrm{m}$ PVDF membrane. The anti-A $\beta$ 6E10 antibody was used to detect the fibrillar $A \beta_{1-40}$ preparation, whereas the anti-A $\beta$ 4G8 antibody was used for tissue lysates (Table 1). A $\beta$ bands were developed by the ECL method. For the membrane containing tissue lysate proteins, it was stripped and re-processed for GAPDH detection. The intensity of high-molecular species $\mathrm{A} \beta(\mathrm{MW}>95 \mathrm{kDa})$ and GAPDH $(36 \mathrm{kD})$ was independently measured using Image $J$ and converted into ratios of $A \beta$-to-GAPDH. The final relative intensity ratio of $A \beta$-to-GAPDH was normalized to the youngest age group of 2.5 months.

\section{ELISA for $A \beta$}

A chemiluminescent ELISA assay specific for the detection of $A \beta x-40$ isoform was used to quantify $A \beta$ in the vitreous of rat eyes (BioLegend, Dedham, MA). 6month-old $(N=4)$ and 11.5 -month-old $(N=6)$ rats were sacrificed for vitreous collection. Vitreous samples were diluted with the HRP detection antibody at a ratio of 1:1. After $18 \mathrm{~h}$ of detection antibody incubation at $4{ }^{\circ} \mathrm{C}$, the ELISA plate was then incubated with chemiluminescent substrates for $15 \mathrm{~s}$ and imaged with a microplate 
reader (Synergy H1, BioTek, Winooski, VT). A nonlinear 4-parameter regression model was used to generate the standard curve to calculate $A \beta$ concentrations of all vitreous samples (Gen5 version 2.04.11, BioTek).

\section{Suspension array for IL-1 $\beta$ and IL-18}

An ELISA-based cytokine assay for the mature, secreted products of the inflammasome, IL-1 $\beta$ and IL-18, was carried out (Bio-Plex 200 System, Bio-Rad Laboratories, Hercules CA). Vitreous from rat eyes in groups 3-4 were pooled. Experiments were carried out following methods in our earlier publication [28].

\section{Statistical analyses}

Non-parametric tests were used throughout the study. For and 5a, b, e-g), a Mann-Whitney $U$ test (one-tailed) was used. For the three group comparisons, a Kruskal-Wallis and post hoc Dunn's multiple comparisons test was used to determine differences among age groups (Fig. 1a, b) or among stimulation regimens (Fig. 2c). All analyses were conducted with GraphPad Prism version 6.00 for Windows (GraphPad Software, La Jolla, CA). Statistical significance was set at $p \leq 0.05$.

\section{Results}

Age-dependent increases of MAC, $A \beta$, and NF-KB in the RPE/choroid

In this study, we first asked whether MAC deposits increase in normal aging and, if so, is it related to inflammasome activation in the RPE/choroid. A significant increase in MAC (MW > $580 \mathrm{kDa})$ was evident in the RPE/choroid

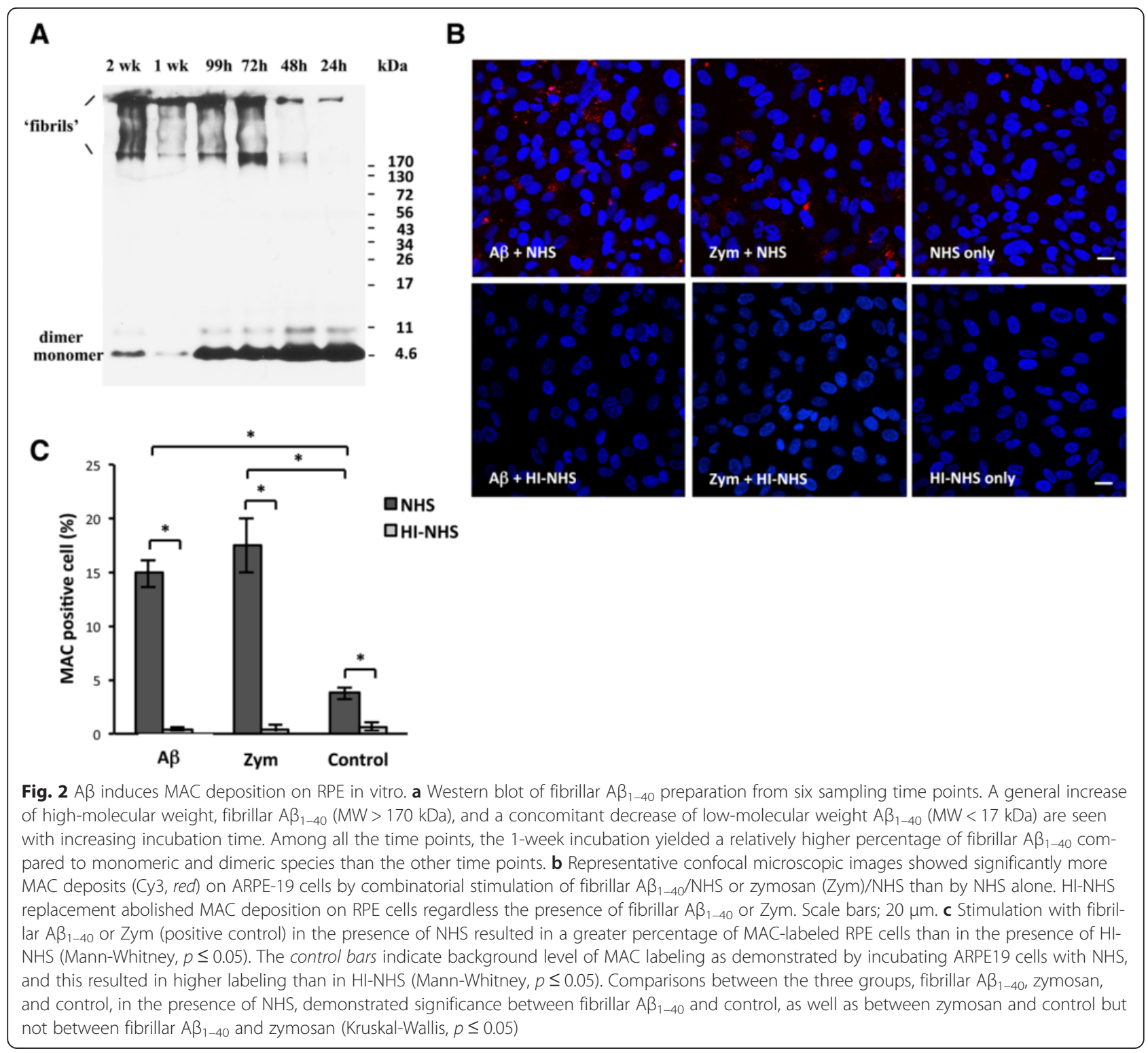




\section{A}

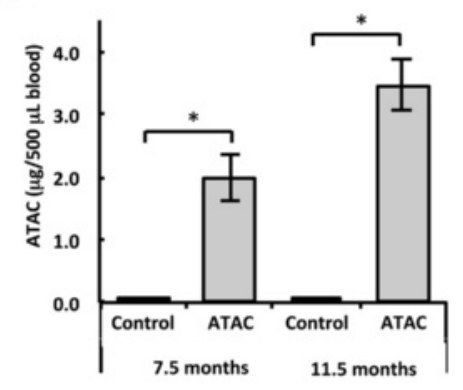

B

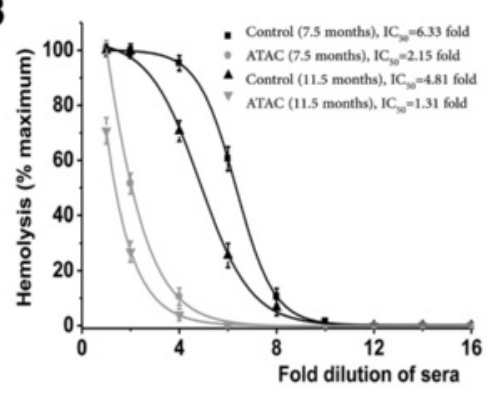

C

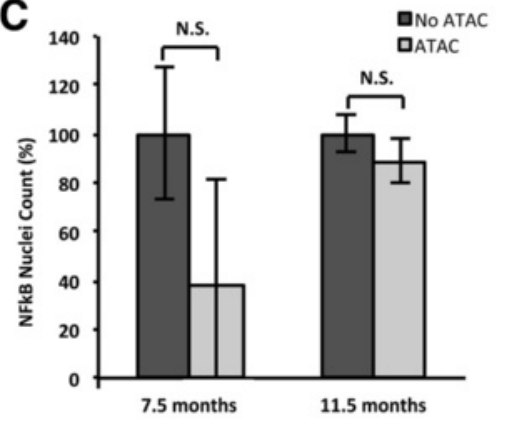

D
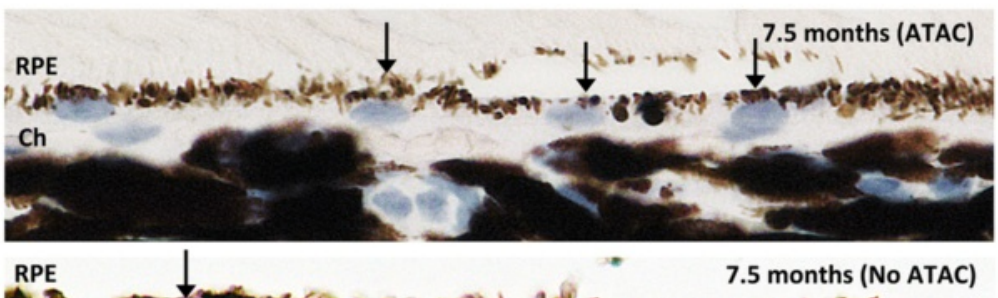

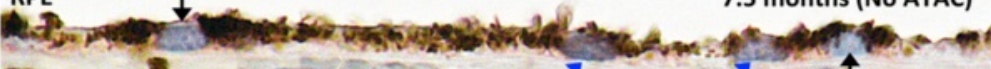

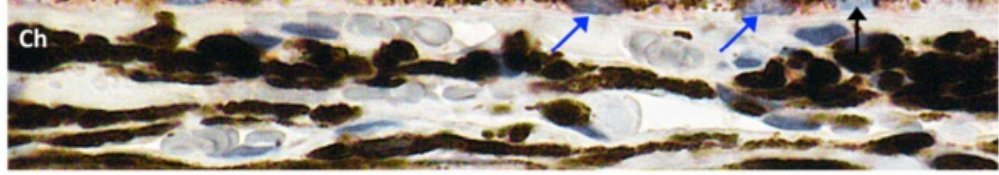

11.5 months (ATAC)

RPE

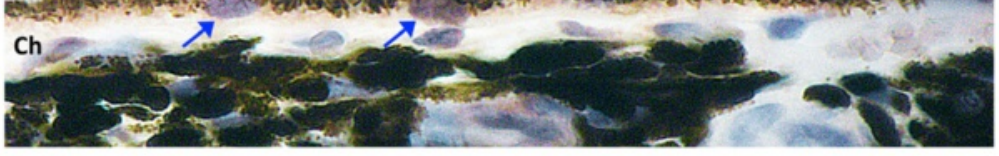

RPE

11.5 months (No ATAC)

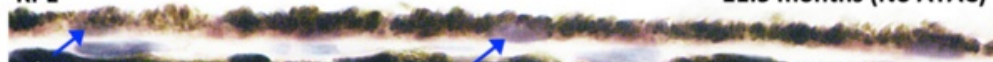
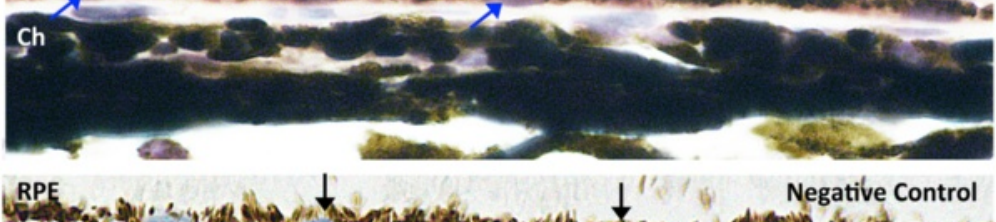

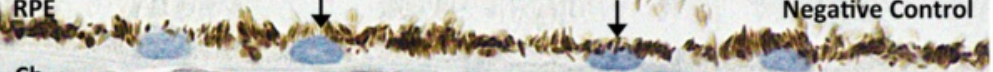

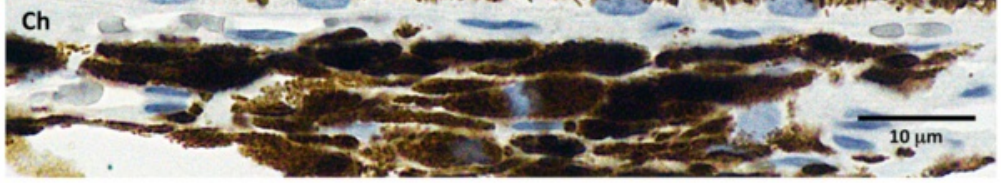

$\mathbf{F}$
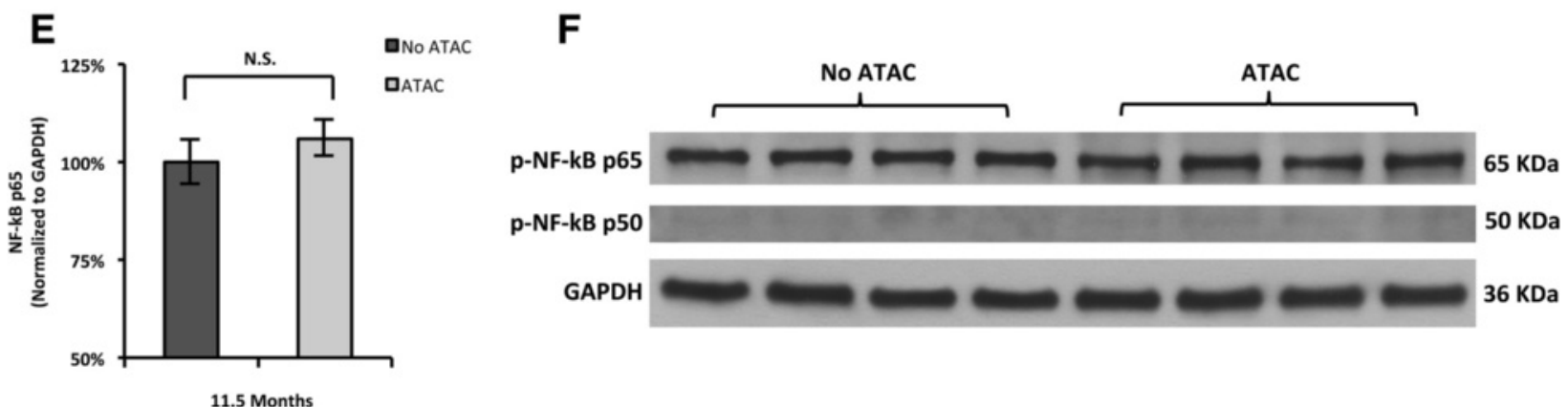

Fig. 3 (See legend on next page.) 
(See figure on previous page.)

Fig. 3 Systemic ATAC administration did not alter NF-KB activation in RPE. a The amount of ATAC in blood was measured after 40 days of drug administration in 7.5-month-old $(1.98 \mu \mathrm{g} / 500 \mu \mathrm{L})$ and in 11.5-month-old (3.5 $\mu \mathrm{g} / 500 \mu \mathrm{L})$ animals. Animals treated with ATAC showed significantly higher ATAC blood concentrations than age-matched controls without ATAC treatment at both ages (Mann-Whitney, $p \leq 0.05$ ). $\mathbf{b}$ The degree of inhibition on total complement activation by ATAC was measured by a CH50 hemolysis assay. Dilutions of the sera containing different levels of ATAC were performed to calculate the half maximal inhibitory concentration $\left(I_{50}\right)$ for total complement activity. Higher $I C_{50}$ values proportionally reflect higher levels of complement activity. Note that the $I_{50}$ levels are lower (i.e., curves shifted to the left) for ATAC-treated animals compared to untreated controls at both ages. c ATAC administration did not affect NF-KB activation in RPE at both ages of 7.5 and 11.5 months (Mann-Whitney, $p>0.05)$. d Representative micrographs of NF-kB p65 immunoreactivity in RPE/choroid from each group in c. RPE cells that demonstrate NF-KB p65 nuclear translocalization have purple nuclei and are marked by blue arrows. Unlabeled RPE nuclei are counterstained with hematoxylin (blue only) and are marked by black arrows. Scale bar; $10 \mu \mathrm{m}$. RPE retinal pigment epithelium, Ch choroid. e, f RPE/choroid tissue lysates from 11.5-month-old rats with ATAC administration contained the same amount of phosphorylated p65 subunit as in rats without ATAC in drinking-water (Mann-Whitney, $p>0.05$ ). The level of phosphorylated p50, however, was extremely low in both groups

homogenates of rats ranging in age from 2.5 to 11.5 months using western blot. The normalized MAC levels were 1.88 -fold higher at 7.5 months and 2.75-fold higher at 11.5 months when compared to the samples obtained from 2.5-month-old rats (Fig. 1a).

$\mathrm{A} \beta$ is a known pathological activator of complement cascade in Alzheimer's disease (AD) [29]. Its ocular presence has been reported in drusen of postmortem eyes [30] and in rodent eyes [31]. To correlate $A \beta$ accumulation with MAC formation, we semi-quantitatively compared the levels of high-molecular weight $A \beta$ species $(\mathrm{MW}>95 \mathrm{kDa})$ among the RPE/choroid homogenates from different ages. We found an age-dependent increase of high-molecular weight $\mathrm{A} \beta$ from 2.5 to 11.5 months (Fig. 1b). Based on the knowledge that biosynthesized $A \beta$ is present in both retina and the vitreous compartment of the eye [32], we quantified the $\mathrm{A} \beta$ in rat vitreous samples at two ages. With increasing age, the vitreal $A \beta$ concentration increased, by almost 80 -fold, from $7.49 \pm 5.16 \mathrm{pg} / \mathrm{mL}$ at 6 months to $599.10 \pm$ $159.25 \mathrm{pg} / \mathrm{mL}$ at 11.5 months of age (Fig. 1c).

To support these results, we also assessed MAC formation and $A \beta$ accumulation in retinal cross sections by immunohistochemistry. We demonstrated that there are increasingly higher levels of immunoreactivity of both MAC and $\mathrm{A} \beta$ in the 11.5 month animals compared to the 7.5-month-old animals, particularly in the choroid and the basal side of RPE (Fig. 1d, e, g, h).

$\mathrm{NF}-\mathrm{kB}$ is a major transcription factor that responds to a variety of pro-inflammatory signals by nuclear translocalization to upregulate the expression of target genes. Previously, we demonstrated that $A \beta$ activates NF- $\kappa B$, which can be specifically inhibited by NF- $\mathrm{kB}$ antagonists (e.g., vinpocetine or BAY 11-7082) [28]. In the present study, by using an antibody targeting the phosphorylated p65 subunit of the translocated NF-kB, we observed an increase in the percentage of RPE nuclei harboring the phosphorylated p65 subunit, mirroring the age-related increase we observed with both MAC and $\mathrm{A} \beta$ (Fig. 1f, i).

\section{$A \beta$ promotes MAC formation in cultured ARPE-19 cells}

The AD literature suggests that $A \beta$ binds to $C 1 q$ and thereby promotes the classic complement cascade [29]. To further understand the relationship between MAC and $\mathrm{A} \beta$ in the RPE/choroid, we undertook stimulation studies to assess MAC formation on RPE in vitro. Cells were stimulated with $0.3-\mu \mathrm{M}$ fibrillar $\mathrm{A} \beta_{1-40}(\mathrm{MW}>170 \mathrm{kDa})$, which was prepared from synthetic $A \beta_{1-40}$ peptide and tested by western blot. In the presence of $25 \%$ NHS, we observed MAC deposition on cells as ascertained by immunocytochemistry with an anti-MAC antibody and imaged by confocal microscopy. MAC formation was prevented in control experiments in which cells were incubated with $25 \%$ HI-NHS. Levels of MAC resulting from fibrillar $\mathrm{A} \beta_{1-40}$-stimulation were compared to MAC deposition on cells treated with zymosan (positive control) or serum-free medium (negative control) in the presence of NHS or HI-NHS. NHS alone resulted in $3.73 \%$ of RPE cells positive for MAC. However, when combined with fibrillar $\mathrm{A} \beta_{1-40}$ or zymosan, MAC deposition increased to $14.91 \%$ and $17.52 \%$ of total RPE cells counted, respectively (Fig. 2).

\section{ATAC did not affect local NF-KB activation in RPE}

While ATAC inhibits complement cascade, it is unclear whether systemic administration of ATAC would reduce local inflammation in the eye. To test this, animals were treated with oral administration of ATAC in drinkingwater $(60 \mathrm{mg} / 100 \mathrm{~mL})$ for 40 days. Animals readily accepted drinking-water laced with ATAC ad libitum, and no overt signs of side effects or toxicity were noted, consistent with our earlier studies in which ATAC was given in food [19].

After 40 days, the average ATAC level, as measured by fluorescence spectroscopy, was 1.98 and $3.5 \mu \mathrm{g} / 500 \mu \mathrm{L}$ in the 7.5 and 11.5-month-old ATAC-treated rats, respectively. As expected, no appreciable amount of ATAC was evident in control rats at either age group (Fig. 3a). A CH50 assay, which measures the amount of hemolysis in blood due to complement activation, has been used 


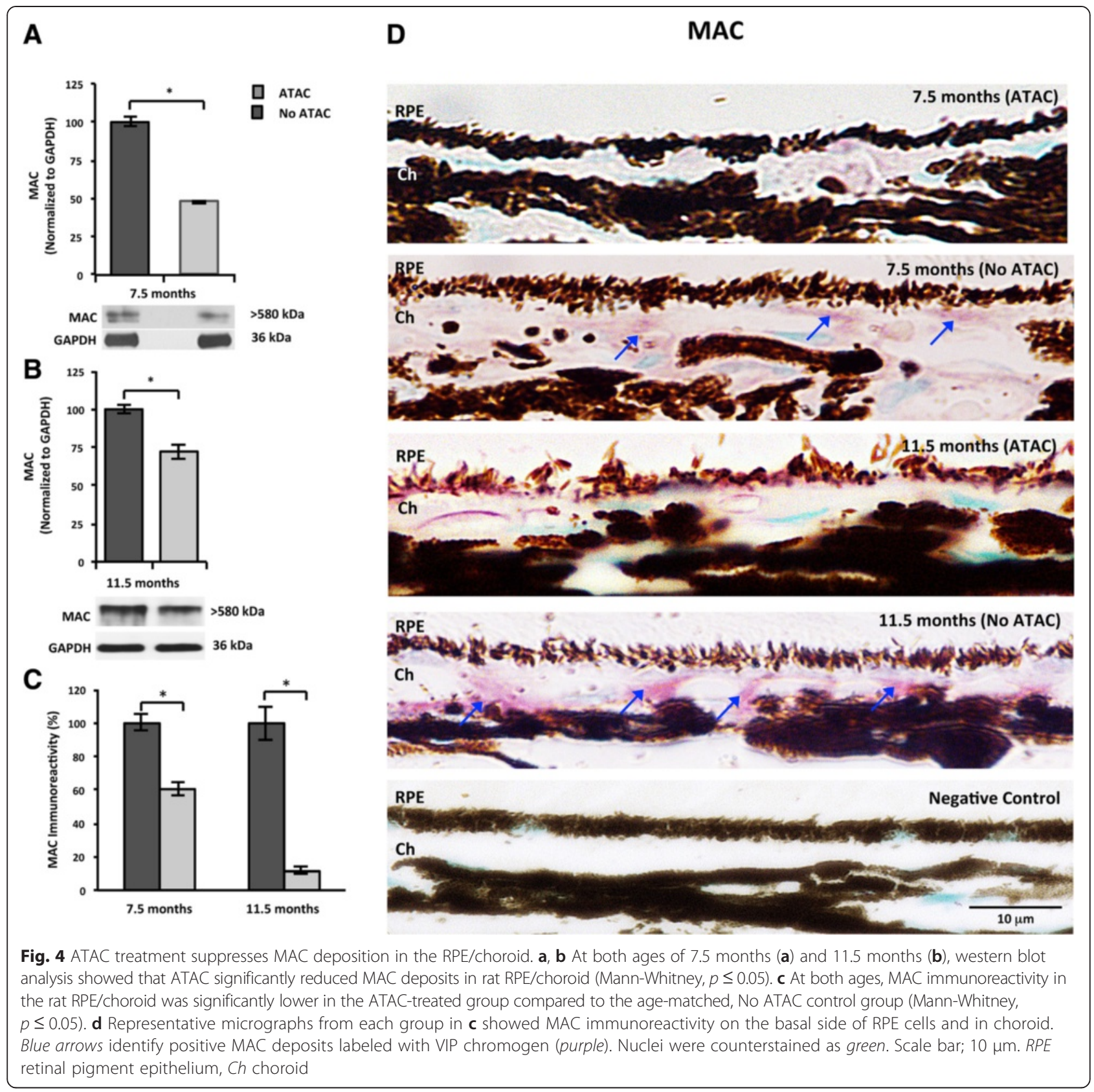

before as a surrogate marker for complement activity both clinically and in experimental studies [19, 33]. Our results showed that sera from the ATAC-treated animals displayed a significant three- to fourfold decrease in hemolysis relative to the sera of the control animals in both age groups studied, thus confirming that orally administered ATAC was present and effective at inhibiting complement activation in the sera of treated rats (Fig. 3b). Next, we assessed the nuclear translocation of the p65 subunit in RPE after ATAC treatment. Intriguingly, systemic administration of ATAC did not change NF- $\mathrm{kB}$ p65 nuclear translocation when compared to control animals at 7.5 or
11.5 months old (Fig. 3c, d). Further western blot analyses of phosphorylated NF- $\mathrm{kB}$ p65 and p50 subunits in 11.5month-old rats supported this, and no significant difference in normalized band intensity was found between animals receiving ATAC or drinking-water (Fig. 3e, f).

\section{ATAC reduced MAC deposition in the RPE/choroid}

Our earlier studies showed that ATAC was effective at decreasing MAC in the central nervous system $[19,20]$, and our next question was whether the observed systemic level of ATAC was sufficient to inhibit MAC formation locally in the eye. To answer this, ATAC-treated 


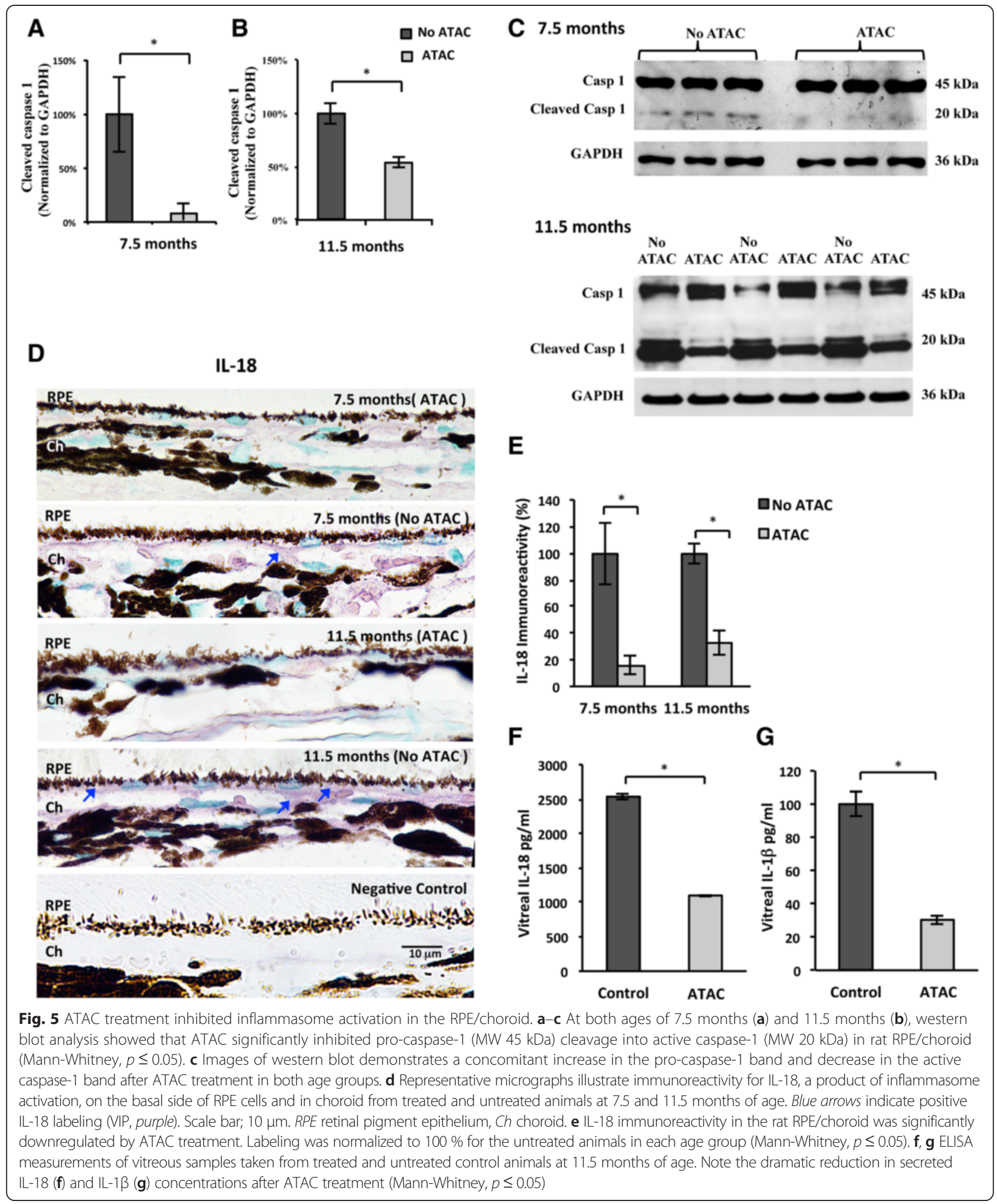

animals (7.5 and 11.5 months old) were sacrificed, and tissue lysate of RPE, choroid, and BM underwent western blot analysis. At both ages, animals treated with ATAC demonstrated less MAC deposits $(\mathrm{MW}>580 \mathrm{kDa})$ in the
RPE/choroid compared to non-ATAC-treated animals. Furthermore, ATAC treatment was more effective at suppressing MAC in the younger group (7.5 months old). This is intriguing, as the younger group demonstrated a lower 
ATAC concentration in sera $(1.98 \mu \mathrm{g} / 500 \mu \mathrm{L})$, but with a proportionally greater inhibition of MAC (50\% inhibition) compared to the older group with $3.5 \mu \mathrm{g} / 500 \mu \mathrm{L}$ ATAC in sera, yet only $25 \%$ inhibition of MAC (Figs. $3 a$ and $4 a, b)$. To better understand the distribution of MAC in the ocular compartments after systemic ATAC, we assessed MAC in retinal cross sections by immunohistochemistry. MAC immunoreactivity was robust in the choroid and BM of non-ATAC-treated rats at both ages, and it was reduced by ATAC treatment at both ages (Fig. 4c, d).

\section{ATAC suppressed inflammasome activation in the RPE/ choroid}

Earlier studies in non-ocular systems suggest that MAC formation is a potential trigger for inflammasome activation $[15,16]$. Here we used an inhibitor of MAC, ATAC, to suppress inflammasome activation in the RPE/choroid. To test whether MAC promotes inflammasome activation, we first examined the level of pro-caspase-1 (MW $45 \mathrm{kDa}$ ) cleavage in RPE/choroid homogenates using western blot. At both ages tested (7.5 and 11.5 months), ATAC successfully lowered cleaved caspase-1 (MW $20 \mathrm{kDa}$ ) by 90\% (7.5 months old) and by $~ 50 \%$ (11.5 months old), when compared to untreated controls (Fig. $5 \mathrm{a}-\mathrm{c}$ ). Next, we assessed the levels of two mature products of inflammasome activation, IL-1 $\beta$ and IL-18. Compared to the ATAC group, we found that IL-18 immunoreactivity was higher in the untreated rat RPE/choroid. On closer visual examination, it was evident that the majority of the IL-18 immunolabeling was located to the basal side of RPE and at the RPE/choroid interface (Fig. $5 \mathrm{~d}$, e). We next tested secreted levels of IL-1 $\beta$ and IL-18 in the vitreous by custom-made ELISA assays. Secreted levels of IL-1 $\beta$ and IL-18 were 3and 2.5-fold lower in the vitreous of animals treated with ATAC, respectively, compared to the untreated agematched controls (Fig. 5f, g).

\section{Discussion}

With normal aging, the RPE/choroid complex undergoes many changes including drusen deposition, thickening of $\mathrm{BM}$, and thinning of the choroid. The RPE also undergoes a number of age-associated changes, including loss of melanin granules, accumulation of lipofuscin, changes in pro-inflammatory cytokine secretion, and even cell death [34, 35]. However, the cellular mechanisms underlying these changes in the RPE/choroid remain largely unknown. Here, we provide a new perspective by investigating the relationship among aging, MAC formation, and inflammasome activation.

\section{$A \beta$ facilitates MAC formation and MAC-induced inflamma- some activation in the RPE/choroid}

In $\mathrm{AD}, \mathrm{A} \beta$ is a known activator of the classic complement pathway [36, 37]. In the eye, it is also abundant, co-localizes with complement factors in drusen, and demonstrates an age-associated increase [38]. We previously showed by pathway analysis (Ingenuity, GSEA) that the complement system is triggered by $A \beta$ stimulation of RPE in vitro [22]. However, little has been done to assess the potential interaction between $A \beta$ and the complement terminal product, MAC. Here we report age-associated increases in MAC and $A \beta$ in the RPE/ choroid complex and soluble $\mathrm{A} \beta$ in the vitreous fluids (Fig. 1). The observed age-associated MAC formation in rat $\mathrm{RPE} /$ choroid is consistent with our earlier findings of MAC deposition in BM and choroid of older postmortem human eyes [10]. Since MAC and $A \beta$ are located at the interface of RPE and choroid, we assessed MAC formation on RPE in the presence of $A \beta$ and NHS and showed for the first time that fibrillar $A \beta$ is an effective inducer of the complement cascade resulting in MAC deposition (Fig. 2). MAC mediated inflammasome activation was shown previously in cells derived from bone marrow and lung epithelial cells in vitro $[15,16]$. Our data support their findings and extend it to an ocular cell type, the RPE.

From our work, and those of others, it is plausible that the inhibition of MAC in the RPE/choroid will dampen inflammasome activation in RPE. We found that ATAC administration concomitantly prevented the full-length caspase-1 from being cleaved into an enzymatically mature caspase-1 p20 subunit, the signature event of inflammasome activation in the same animals in which we observed a reduction in MAC levels (Figs. 4 and 5). However, NF- $\mathrm{kB}$ activation, a primer for inflammasome activation, was not affected by ATAC treatment, demonstrated by statistically equivalent amounts of the phosphorylated p65 subunit in both retinal sections and RPE/choroid lysates (Fig. 3). Intriguingly, the phosphorylated p50 subunit's level was extremely low in both ATAC and drinking-water-treated rats. Although the p50/p65 heterodimer is considered the primary form of NF- $\mathrm{kB}$ complex in a wide variety of cell types, there are other active NF$\kappa \mathrm{B}$ dimeric combinations that do not require either one or both of them [39]. All of these suggest that ATAC's inhibitory effects spare NF- $\mathrm{B}$ activation that involves p65 or p50 and are specific for MAC. Hence, the significant reduction in inflammasome activation products, IL-18 and IL-1 $\beta$, which we observed after ATAC treatment, is likely due to inefficient post-translational processing by mature caspase-1, rather than due to altered pro-IL-18 and proIL-1 $\beta$ production by NF- $\mathrm{KB}$ pathway (Fig. 5). Whether and how the specific inhibition of NF- $\mathrm{kB}$ pathway can in turn affect MAC formation remains elusive and is beyond the scope of the current study. Although the literature suggests NF- $\mathrm{kB}$ signaling regulates multiple genes in the complement cascades, such as CFB, C3, and C4, our data indicates no effects on $\mathrm{C} 5 \mathrm{a}$ production when $\mathrm{NF}-\mathrm{kB}$ 
activation is blocked by vinpocetine in vivo (see Additional file 1), and thus, likely not affecting MAC formation as well [28, 40-42].

\section{Age-associated differences in MAC deposition and MAC inhibition by ATAC}

Another interesting outcome of our study is the difference in ATAC efficacy in the two age groups tested. The younger rats had lower ATAC levels in blood $(\sim 2 \mu \mathrm{g} / 500 \mu \mathrm{L})$ than the older rats $(\sim 3.5 \mu \mathrm{g} / 500 \mu \mathrm{L})$ (Fig. 3), yet there was a proportionally greater decrease in MAC, caspase- 1 cleavage, and secreted IL-18 in the younger rats compared to the older group, suggesting that ATAC treatment was more efficacious in the younger group (Figs. 4 and 5). The exact mechanism behind this finding is not clear. One possible explanation is that, with age, there is more $A \beta$ accumulation in the rat eye, leading to more robust NF- $\mathrm{kB}$ activation (p65 nuclear translocalization) and more MAC deposition, which is not proportional to the increase in ATAC concentration, or its activity, and thus overwhelmed ATAC's suppressive effects leading to reduce efficacy in the older rats compared to that observed in younger rats (Figs. 1 and 2).

\section{Conclusions}

In summary, we have shown an age-dependent increase in $\mathrm{A} \beta, \mathrm{MAC}$, and NF- $\mathrm{kB}$ in rat RPE/choroid. We have also demonstrated that $A \beta$, a drusen component, is an effective priming signal for NF- $\mathrm{kB}$ activation in vitro and in vivo [28] and promotes the NLRP3 inflammasome activation in the rat eye [21]. Suppression of MAC leads to a concomitant suppression of NLRP3 inflammasome activation measured by caspase- 1 cleavage and secretion of mature IL-18 and IL-1 $\beta$ as depicted in the schematic summary (Fig. 6). An inherent limitation of this study is that rodents do not have a macula/fovea, and thus renders this animal model less useful as it does not reproduce "macular" disease. However, this model is useful to understand the basic, cellular changes in the retina that are associated with chronic inflammation, aging, and age-related retinal diseases. Our work suggests that MAC-induced NLRP3 inflammasome activation may be an important cause of
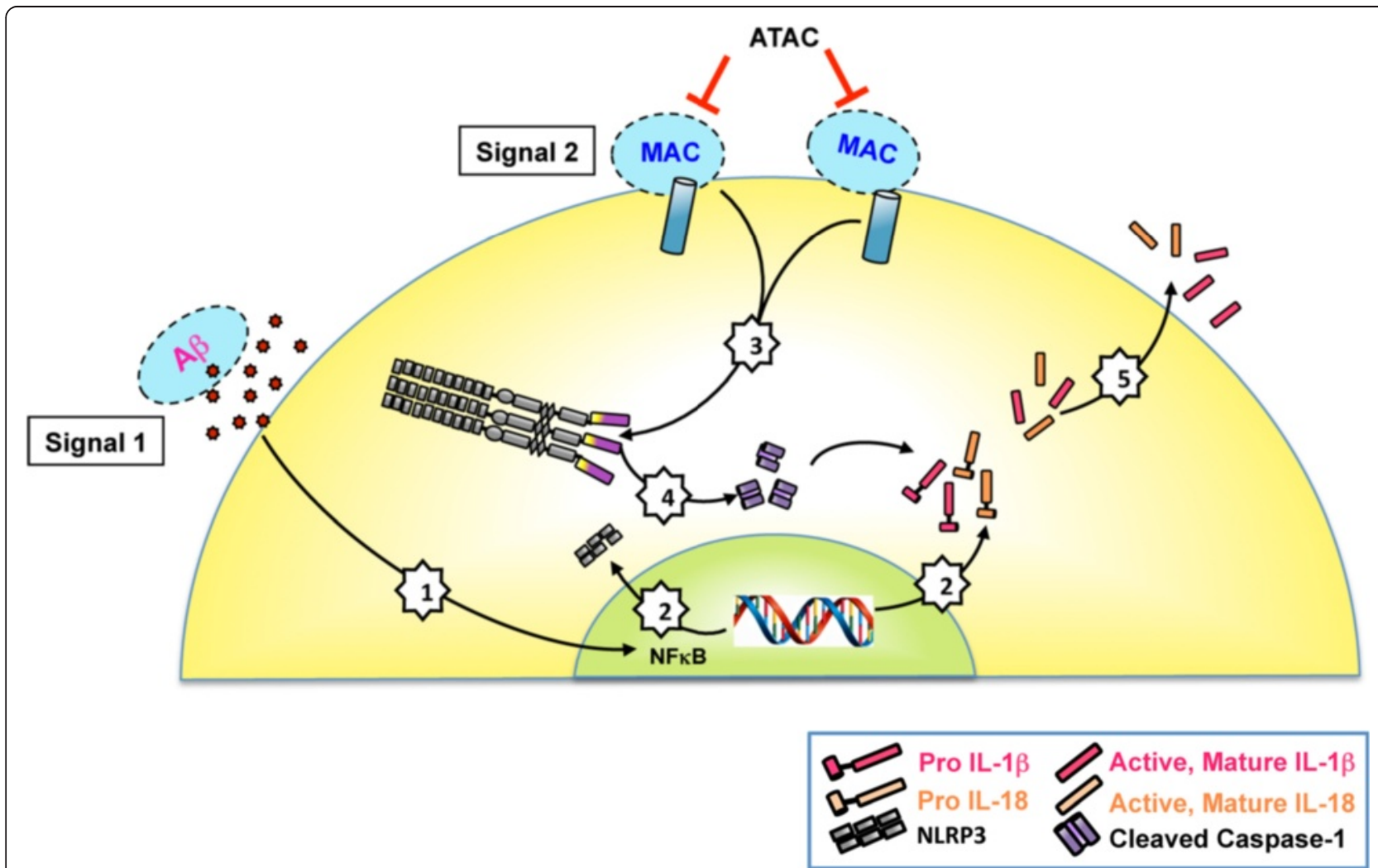

Fig. 6 Proposed inflammasome activation mechanisms with $A \beta$ and MAC in RPE/choroid. Age-associated changes in RPE/choroid include an increased accumulation of $A \beta$ that acts as a "Signal 1" to activate the NF-KB pathway (1). This upregulates the transcription of NLRP3, pro-IL-18 and pro-IL-1 $\beta$ (2). Next, assembly and activation of the NLRP3 inflammasome is triggered by MAC deposition ("Signal 2") on the RPE cell membrane (3). NLRP3 activation results in pro-caspase-1 auto-cleavage (4). The cleaved caspase-1 then functions as a cytokine-processing enzyme to facilitate the production and secretion of active, mature IL-18 and IL-1 $\beta$ (5). ATAC compound works as a MAC inhibitor, suppressing MAC-induced inflammasome activation on RPE 
the chronic pro-inflammatory environment in the outer retina of a normal aging eye.

\section{Additional file}

\section{Additional file 1: $\mathrm{C} 5 \mathrm{a}$ is not affected by Vinpocetine-mediated}

NF-KB inhibition. Description of data: Since the intraocular $A \beta_{1-40}$ injection has been previously implicated in promoting NF-KB activation and NLRP3 inflammasome activation [21], we assessed the level of activated $\mathrm{C5}$ (C5a) as a surrogate marker for complement activation and MAC formation when NF-KB activity was specifically inhibited by vinpocetine. Western blot of retina protein lysates shows equal amounts of C5a (MW 41 $\mathrm{KDa}$; rabbit polyclonal C5a complement antibody, cat\# 250565) in the vinpocetine-treated group, when compared to vehicle controls (Mann-Whitney, $p>0.05 ; N=5$ ). For a full description of the experimental procedures, readers are referred to our previous publication [28].

\section{Competing interests}

$T Z, J G, J V, E T, A W, S C, J Z C$, and JAM declare that they have no competing interests. JPG, ML, and PLM declare a licensed patent (Aurin Biotech Inc.) relevant to the work.

\section{Authors' contributions}

$T Z, J G, J V, E T, A W$, and SC performed the experiments, analyzed the data, and participated in manuscript writing. JZC designed the study, performed the experiments, analyzed the data, and participated in manuscript writing. JPG and ML performed the experiments and analyzed the data. PLM designed the study and analyzed the data. JAM designed the study, obtained funding, analyzed the data, and critically revised the manuscript. All authors read and approved the final manuscript.

\section{Acknowledgements}

The authors acknowledge Matthew Wong and Elliott To for expert technical assistance and acknowledge the support by Vancouver Hospital + UBC Foundation. This study was funded by Canadian Institutes of Health Research grants (CIHR MOP 97806, MOP 126195) to JAM.

\section{Grant support}

CIHR (MOP 97806, MOP 126195) and VGH + UBC Hospital Foundation

\section{Author details}

'Department of Ophthalmology and Visual Sciences, Faculty of Medicine, University of British Columbia, 2550 Willow Street, Vancouver V5Z 3N9BC, Canada. ${ }^{2}$ Kinsmen Lab of Neurological Research, University of British Columbia, Vancouver, BC, Canada.

Received: 10 February 2015 Accepted: 4 June 2015

Published online: 24 June 2015

\section{References}

1. Wong WL, Su X, Li X, Cheung CM, Klein R, Cheng CY, et al. Global prevalence of age-related macular degeneration and disease burden projection for 2020 and 2040: a systematic review and meta-analysis. Lancet Glob Health. 2014:2:e106-16.

2. Ardeljan D, Chan CC. Aging is not a disease: distinguishing age-related macular degeneration from aging. Prog Retin Eye Res. 2013;37:68-89.

3. Rodriguez-Muela N, Koga H, Garcia-Ledo L, de la Villa P, de la Rosa EJ, Cuervo AM, et al. Balance between autophagic pathways preserves retinal homeostasis. Aging Cell. 2013;12:478-88.

4. Chen $\mathrm{M}$, Muckersie $\mathrm{E}$, Forrester $\mathrm{J}, \mathrm{Xu}$. Immune activation in retinal aging: a gene expression study. Invest Ophthalmol Vis Sci. 2010;51:5888-96.

5. Ricklin D, Hajishengallis G, Yang K, Lambris JD. Complement: a key system for immune surveillance and homeostasis. Nat Immunol. 2010;11:785-97.

6. Anderson DH, Radeke MJ, Gallo NB, Chapin EA, Johnson PT, Curletti CR, et al. The pivotal role of the complement system in aging and age-related macular degeneration: hypothesis re-visited. Prog Retin Eye Res. 2010;29:95-112.

7. Mullins RF, Schoo DP, Sohn EH, Flamme-Wiese MJ, Workamelahu G, Johnston $\mathrm{RM}$, et al. The membrane attack complex in aging human choriocapillaris: relationship to macular degeneration and choroidal thinning. Am J Pathol. 2014:184(11):3142-53.

8. Mullins RF, Dewald AD, Streb LM, Wang K, Kuehn MH, Stone EM. Elevated membrane attack complex in human choroid with high risk complement factor H genotypes. Exp Eye Res. 2011;93:565-7.

9. Cao S, Ko A, Partanen M, Pakzad-Vaezi K, Merkur AB, Albiani DA, et al. Relationship between systemic cytokines and complement factor $\mathrm{H}$ Y $402 \mathrm{H}$ polymorphism in patients with dry age-related macular degeneration. Am J Ophthalmol. 2013;156:1176-83.

10. Seth A, Cui J, To E, Kwee M, Matsubara J. Complement-associated deposits in the human retina. Invest Ophthalmol Vis Sci. 2008:49:743-50.

11. $\mathrm{Xu} \mathrm{H}$, Chen M, Forrester JV. Para-inflammation in the aging retina. Prog Retin Eye Res. 2009;28:348-68.

12. Chen H, Liu B, Lukas TJ, Neufeld AH. The aged retinal pigment epithelium/ choroid: a potential substratum for the pathogenesis of age-related macular degeneration. PLoS One. 2008;3:e2339.

13. Whitmore SS, Sohn EH, Chirco KR, Drack AV, Stone EM, Tucker BA, et al. Complement activation and choriocapillaris loss in early AMD: Implications for pathophysiology and therapy. Prog Retin Eye Res. 2015;45C:1-29.

14. Lueck K, Wasmuth S, Williams J, Hughes TR, Morgan BP, Lommatzsch A, et al. Sub-lytic C5b-9 induces functional changes in retinal pigment epithelial cells consistent with age-related macular degeneration. Eye (Lond). 2011;25:1074-82.

15. Laudisi F, Spreafico R, Evrard M, Hughes TR, Mandriani B, Kandasamy M, et al. Cutting edge: the NLRP3 inflammasome links complement-mediated inflammation and IL-1 beta release. J Immunol. 2013;191:1006-10.

16. Triantafilou K, Hughes TR, Triantafilou M, Morgan BP. The complement membrane attack complex triggers intracellular $\mathrm{Ca} 2+$ fluxes leading to NLRP3 inflammasome activation. J Cell Sci. 2013;126:2903-13.

17. Tarallo V, Hirano Y, Gelfand BD, Dridi S, Kerur N, Kim Y, et al. DICER1 loss and Alu RNA induce age-related macular degeneration via the NLRP3 inflammasome and MyD88. Cell. 2012;149:847-59.

18. Gao J, Liu RT, Cao S, Cui JZ, Wang A, To E, et al. NLRP3 inflammasome: activation and regulation in age-related macular degeneration. Mediators Inflamm. 2015;2015:11.

19. Lee M, Guo JP, Schwab C, McGeer EG, McGeer PL. Selective inhibition of the membrane attack complex of complement by low molecular weight components of the aurin tricarboxylic acid synthetic complex. Neurobiol Aging. 2012;33:2237-46.

20. Lee M, Guo JP, McGeer EG, McGeer PL. Aurin tricarboxylic acid self-protects by inhibiting aberrant complement activation at the $\mathrm{C} 3$ convertase and C9 binding stages. Neurobiol Aging. 2013;34:1451-61.

21. Liu RT, Gao J, Cao S, Sandhu N, Cui JZ, Chou CL, et al. Inflammatory mediators induced by amyloid-beta in the retina and RPE in vivo: implications for inflammasome activation in age-related macular degeneration. Invest Ophthalmol Vis Sci. 2013:54:2225-37.

22. Kurji KH, Cui JZ, Lin T, Harriman D, Prasad SS, Kojic L, et al. Microarray analysis identifies changes in inflammatory gene expression in response to amyloid-beta stimulation of cultured human retinal pigment epithelial cells. Invest Ophthalmol Vis Sci. 2010;51:1151-63.

23. Sarroukh R, Cerf E, Derclaye S, Dufrene YF, Goormaghtigh E, Ruysschaert JM, et al. Transformation of amyloid beta(1-40) oligomers into fibrils is characterized by a major change in secondary structure. Cell Mol Life Sci. 2011;68:1429-38.

24. Stine WB, Jungbauer $L, Y u C$, LaDu M. Preparing synthetic $A \beta$ in different aggregation states. In: Roberson ED, editor. Alzheimer's Disease and Frontotemporal Dementia, vol. 670. Clifton, NJ: Humana Press; 2011. p. 13-32. Methods in Molecular Biology.

25. Garzon-Rodriguez W, Sepulveda-Becerra M, Milton S, Glabe CG. Soluble amyloid Abeta-(1-40) exists as a stable dimer at low concentrations. J Biol Chem. 1997;272:21037-44.

26. Haass C, Schlossmacher MG, Hung AY, Vigo-Pelfrey C, Mellon A, Ostaszewski $\mathrm{BL}$, et al. Amyloid beta-peptide is produced by cultured cells during normal metabolism. Nature. 1992;359:322-5.

27. Lin H, Bhatia R, Lal R. Amyloid beta protein forms ion channels: implications for Alzheimer's disease pathophysiology. FASEB J. 2001;15:2433-44.

28. Liu RT, Wang A, To E, Gao J, Cao S, Cui JZ, et al. Vinpocetine inhibits amyloid-beta induced activation of NF-kappaB, NLRP3 inflammasome and cytokine production in retinal pigment epithelial cells. Exp Eye Res. 2014;127c:49-58. 
29. Shen Y, Yang L, Li R. What does complement do in Alzheimer's disease? Old molecules with new insights. Transl Neurodegener. 2013;2:21.

30. Isas JM, Luibl V, Johnson LV, Kayed R, Wetzel R, Glabe CG, et al. Soluble and mature amyloid fibrils in drusen deposits. Invest Ophthalmol Vis Sci. 2010;51:1304-10.

31. Hoh Kam J, Lenassi E, Jeffery G. Viewing ageing eyes: diverse sites of amyloid Beta accumulation in the ageing mouse retina and the up-regulation of macrophages. PLoS One. 2010;5.

32. Prakasam A, Muthuswamy A, Ablonczy Z, Greig NH, Fauq A, Rao KJ, et al. Differential accumulation of secreted AbetaPP metabolites in ocular fluids. J Alzheimers Dis. 2010;20:1243-53.

33. Ferriani VP, Barbosa JE, de Carvalho IF. Complement haemolytic activity (classical and alternative pathways), C3, C4 and factor B titres in healthy children. Acta Paediatr. 1999;88:1062-6.

34. Boulton $M$, Dayhaw-Barker $P$. The role of the retinal pigment epithelium: topographical variation and ageing changes. Eye (Lond). 2001;15:384-9.

35. Cao S, Walker GB, Wang X, Cui JZ, Matsubara JA. Altered cytokine profiles of human retinal pigment epithelium: oxidant injury and replicative senescence. Mol Vis. 2013;19:718-28.

36. Rogers J, Cooper NR, Webster S, Schultz J, McGeer PL, Styren SD, et al. Complement activation by beta-amyloid in Alzheimer disease. Proc Natl Acad Sci U S A. 1992:89:10016-20.

37. Velazquez P, Cribbs DH, Poulos TL, Tenner AJ. Aspartate residue 7 in amyloid beta-protein is critical for classical complement pathway activation: implications for Alzheimer's disease pathogenesis. Nat Med. 1997;3:77-9.

38. Johnson LV, Leitner WP, Rivest AJ, Staples MK, Radeke MJ, Anderson DH. The Alzheimer's A beta -peptide is deposited at sites of complement activation in pathologic deposits associated with aging and age-related macular degeneration. Proc Natl Acad Sci U S A. 2002;99:11830-5.

39. Perkins ND. The diverse and complex roles of NF-kappaB subunits in cancer. Nat Rev Cancer. 2012;12:121-32.

40. Huang Y, Krein PM, Muruve DA, Winston BW. Complement factor B gene regulation: synergistic effects of TNF-alpha and IFN-gamma in macrophages. J Immunol. 2002;169:2627-35.

41. Moon MR, Parikh AA, Pritts TA, Fischer JE, Cottongim S, Szabo C, et al.

Complement component C3 production in IL-1 beta-stimulated human intestinal epithelial cells is blocked by NF-kappaB inhibitors and by transfection with ser 32/36 mutant IkappaBalpha. J Surg Res. 1999;82:48-55.

42. Yu DY, Huang ZM, Murakami S, Takahashi M, Nonaka M. Specific binding of a hepatoma nuclear factor to the NF.kappa B/H2TF1 recognition motif found in the C4 promoter, but not in the Slp promoter. J Immunol. 1989;143:2395-400.

\section{Submit your next manuscript to BioMed Central and take full advantage of:}

- Convenient online submission

- Thorough peer review

- No space constraints or color figure charges

- Immediate publication on acceptance

- Inclusion in PubMed, CAS, Scopus and Google Scholar

- Research which is freely available for redistribution

Submit your manuscript at www.biomedcentral.com/submit 